\title{
Influence of Factor Mobility on Chinese Multinationals' ODI Mode Choice: Theoretical and Empirical Analysis
}

\author{
Naixi Liu \\ Department of International Economics, China Foreign Affairs University, Beijing, China \\ Email address: \\ liunaixi@cfau.edu.cn \\ To cite this article: \\ Naixi Liu. Influence of Factor Mobility on Chinese Multinationals' ODI Mode Choice: Theoretical and Empirical Analysis. Journal of \\ Investment and Management. Vol. 9, No. 1, 2020, pp. 31-39. doi: 10.11648/j.jim.20200901.15
}

Received: February 16, 2020; Accepted: February 26, 2020; Published: March 6, 2020

\begin{abstract}
ODI by Chinese multinationals' has grown rapidly in recent decades, and the ratio of M\&A investment to aggregate ODI flow has demonstrated a "W" shape history, while the global ratio has demonstrated an "M" shape history. The recent theoretical progress in new century supplied a new perspective focused on firm heterogeneity such as the firm's factor mobility to explain the diversity of international organization of production choices including the mode choice of ODI. Respectively, we supposed three hypothesizes based on theoretical discussion with combining the new-classical international direct investment theory and the frontier theoretical progress of international organization of production. We use micro level data for more than 2200 large scale ODI transactions by Chinese multinationals to study the relationship between cross-border factor mobility and ODI mode choice with a panel logit estimation. Our results testified all three hypothesizes supposed. Firstly, the results provide evidence that cross-border factor mobility affects the choice between Greenfield and M\&A ODI. Secondly, the results also support the view that ODI mode choices are influenced by characteristics of host economies. The ease of registering property has a positive effect on the probability of choosing Greenfield ODI, while the ease of obtaining credit, enforcing contracts and trading across borders has a positive effect on the probability of choosing M\&A. Finally, we find that the probability of choosing M\&A increases when a multinational belongs to an industry that relies on obtaining natural resources or investment takes place in an economy with high labor costs. In general, our research shows that ODI mode choices by Chinese multinationals varies across host countries and industries due to the internal trade-off impact from the firm heterogeneity such as factor mobility. Moreover, at the end we discussed two short boards of our empirical process due to the data shortage problem and take a positive prospect for the following research.
\end{abstract}

Keywords: Factor Mobility, Chinese Multinationals, ODI Mode Choice

\section{Introduction}

Outward direct investment (ODI) by Chinese multinationals' has grown rapidly in recent decades. Much of this growth has been in the form of Mergers and Acquisitions (M\&A) rather than Greenfield investment. However, the ratio of M\&A investment to aggregate ODI flow has demonstrated a "W" shape history, as opposed to the global ratio which has demonstrated an "M" shape history. This raises the question as to why some Chinese multinationals prefer M\&A while others prefer Greenfield investments. Stated differently, how can we explain the behavior of Chinese multinationals in terms of ODI mode choice?

Some of the recent research on ODI has focused on firm heterogeneities to explain diversity of international organization of production choices. Thus, for example, Nocke and Yeaple[1] developed a general subgame perfect equilibrium model to show that the cross-border factor mobility is the essence of heterogeneity. Prior to their work, firm heterogeneity was largely reflected in differences in total factor productivity and its potential impact on ODI patterns across industries and country-pairs.

From this perspective, the question is whether cross-border factor mobility affects multinationals' ODI mode choices. In this paper, following the work of Nocke and Yeaple [1], we examine three hypotheses relating to mode choice, and test these empirically using data from over two thousand large scale ODI transactions by Chinese multinationals. Our work makes four contributions: 1) it is the first empirical study of Chinese multinationals' ODI mode choice that examines the 
role of firm heterogeneity using transaction level data; 2) the results provide significant empirical evidence in support of the hypothesis that cross-border factor mobility affects the choice between Greenfield and M\&A and shows how choices vary across industries; 3) we show how ODI mode choices vary across countries, indicating that cross-border factor mobility of capabilities is influenced by characteristics of host economies; and 4) we show that the probability of choosing M\&A increases when a multinational belongs to an industry that relies on obtaining natural resources or when ODI is directed to a host economy with high labor costs.

The organization of the remainder of the paper is as follows: following the presentation of some additional background information three hypothesizes are presented; this is followed by a description of the dataset; we then describe the estimating equation and variables; based on the estimation results we discuss their implications; finally, we summarize our conclusions and their contribution.

\section{Background}

The annual flow of Chinese ODI increased from 0.83 billion USD in 1990 to 183.1 billion USD in 2016; during the same period global ODI outflow increased from 243.9 billion USD to $1,452.5$ billion USD. As shown in figure 1, while global ODI flow has been sensitive changes in business conditions (e.g., the so-called dotcom bubble of the late 1990s and the global financial crisis of 2007-8) Chinese ODI annual flow has risen steadily since the country joined the World Trade Organization in November 2001. China has become the second largest ODI outflow country in the world since 2015, and Chinese multinationals now play an important role in the global ODI market.

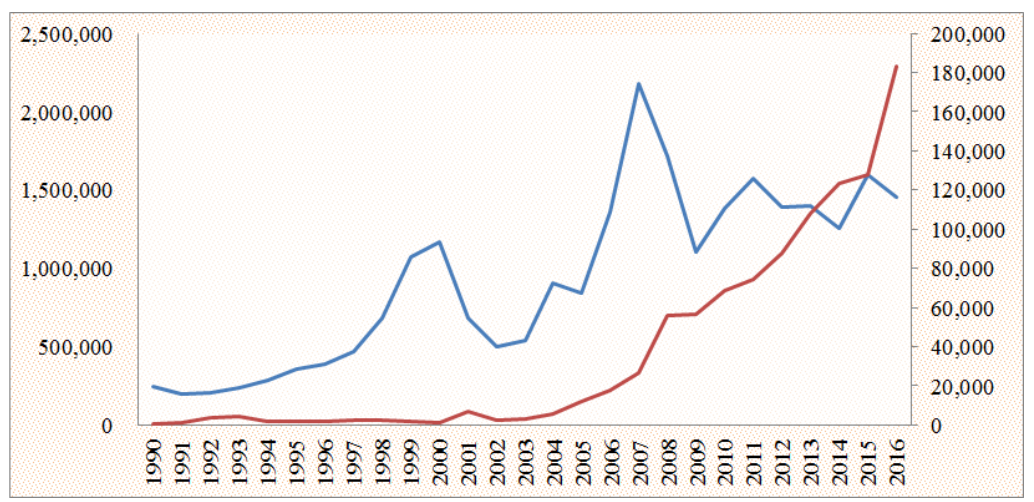

Figure 1. ODI Annual Flow, 1990 - 2016.

Red Curve: Chinese ODI Annual Flow, right axis; Blue Curve: Global ODI Annual Flow, left axis

Data Source: National Bureau of Statistics of China, UNCTAD Statistics

If we turn to the composition of ODI, we see that the historical patterns of global and Chinese ODI differ. Figure 2 demonstrates that global ratio of M\&A activity to total ODI flow has had an "M" shape pattern while the ratio of Chinese annual M\&A activity to Chinese total ODI flow has shown a "W" shape pattern. Although the consensus is that the international business behavior of multinationals is affected by macroeconomic factors[2, 3], it seems that the compositional structure of multinationals' ODI mode choices cannot simply be explained by macroeconomic factors, otherwise ODI by Chinese multinationals should have shown a similar pattern to that globally. In order to examine ODI choices by Chinese multinationals it seems necessary to consider other factors. This prompts us to examine the potential impact of micro factors (firm heterogeneity characteristics) on ODI mode choice.

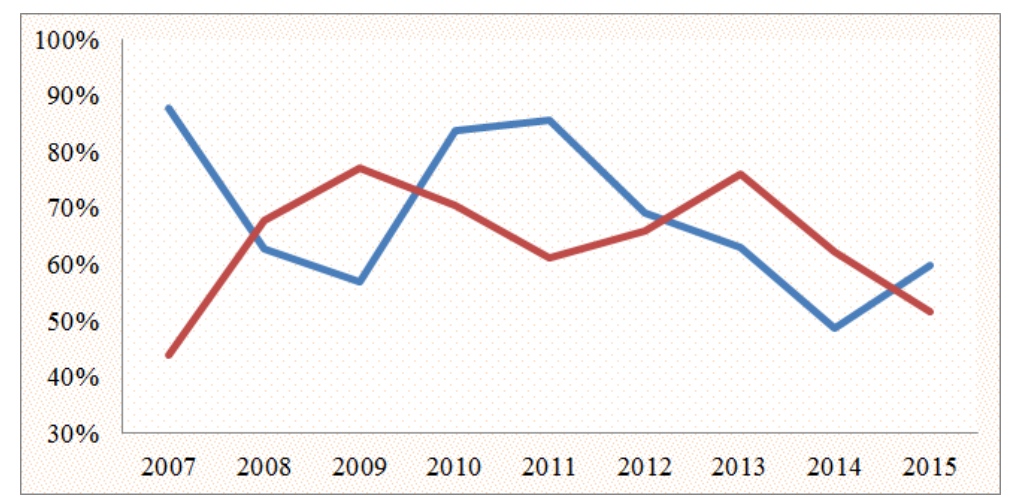

Figure 2. Ratio of annual M\&A amount to total ODI flow, $2007-2015$.

Red Curve: the ratio of global annual M\&A amount to global total ODI flow; Blue Curve: the ratio of Chinese annual M\&A amount to Chinese total ODI flow Data Source: National Bureau of Statistics of China, UNCTAD Statistics 


\section{Theoretical Hypotheses}

In recent decades, researchers have examined the role of firm heterogeneity in ODI behavior. Melitz [4] concluded that firms with higher productivity would engage in foreign market access. Helpman, Melitz and Yeaple [5] conducted a comprehensive study of ODI and reached the conclusion that the most productive firms would engage in ODI; the second most productive would engage in exports; and the least productive would focus on serving the domestic market. Subsequent empirical studies have supported these HMY conclusions $[6,7,8]$.

The HMY framework does not explain why some firms choose Greenfield ODI rather than cross-border M\&A, while others demonstrate the opposite preference. To provide an explanation, Nocke and Yeaple [1] explored the relationship between firm heterogeneity and internationalization. They concluded that in international business, firm heterogeneity does not just include differences in capability but also involves the cross-border factor mobility of that capability.

Nocke and Yeaple [1] developed a general subgame perfect equilibrium model to demonstrate that the international organization of production varies across industries and country-pairs, and that this can be explained by the cross-border factor mobility of capabilities. They conclude that M\&A is more popular in industries requiring immobile capabilities compared to those requiring mobile capabilities. This conclusion shows the firm heterogeneity matters in multinationals' ODI mode choice. In addition, compared to Greenfield ODI, M\&A ODI usually involves firms trading heterogeneous corporate assets to exploit complementarities [9] M\&A investment often requires higher capital support and involves higher risk [10]. This makes it likely that multinational companies will make a tradeoff between pursuing short-term returns based on lower cost and risk and pursuing long term returns based on higher cost and higher risk.

From this prospective, if we take the global market as a unified market without any barriers of ODI, we can have two postulates.

First, in an industry requiring cross-border mobile capabilities, such as technological advantage and management experience, multinationals with higher productivity would prefer Greenfield rather than M\&A so that they can retain these advantages. In contrast firms with lower productivity may prefer M\&A so that they can gain benefits through spillover and learning effects. Empirical studies by Schiffbauer [11] and Stiebale and Trax [12] have demonstrated that M\&A ODI generates these types of benefits.

Second, in an industry requiring cross-border immobile capabilities, such as localization requirements, marketing experience and social relations (established networks), multinationals with higher productivity would prefer M\&A rather than Greenfield ODI so that they can gain existing localization advantages from the local company. Companies with immobile capabilities and lower productivity will only be able to expand abroad by merging with a multinational with higher productivity. As the HMY hypothesis suggests, only the most efficient firms will undertake ODI in entering into the international market, so it is appropriate to suppose that most of the multinationals that demonstrate ODI behavior will have higher levels of productivity. Consequently, it is appropriate to focus only on multinationals and to ignore other firms that operate solely in the domestic market.

In the study by Nocke and Yeaple [1], in order to conduct game theory analysis it is assumed that every company only has one mobile or immobile capability. This is not necessarily the case in reality. A given multinational may have business activities both in industries that require mobile capabilities and in those requiring immobile capabilities or a company may have business in one type of industry but would like to expand into the other. This means that we could observe a multinational company making different ODI mode choices by expanding into different industries or investing in different countries. Nocke and Yeaple [1,9] demonstrated two deductions: (1) the international organization of production varies across industries; (2) the international organization of production in the same industry varies across countries. Based on these two deductions, we state our first two hypothesizes.

Hypothesis I: we expect to observe more $M \& A O D I$ in an industry requiring immobile capabilities and more Greenfield $O D I$ in an industry requiring mobile capabilities. This is based on the conclusion of Nocke and Yeaple[1] and the discussion above.

Hypothesis II: we expect to observe more Greenfield ODI or less M\&A ODI in host countries where there are fewer barriers to the mobility of capability, such as fewer restrictions on ODI, lower business start-up costs or a more mature business environment. ODI mode choices in host countries will be influenced by country characteristics [13, 14, 15]. If there are tighter ODI restrictions, higher business start-up costs etc., it will be harder for multinationals to maintain productivity advantages via Greenfield ODI, and they would have to choose M\&A ODI to overcome the barriers in a host economy.

Dunning [16] identified four common motivations for multinationals' ODI behavior: market development, limited domestic natural resources [17], cost saving/profit enhancing, and access to strategic assets such as technology and management experience. It has been found that multinationals with a cost saving motivation would prefer Greenfield ODI, especially when the origin country has a higher average cost level than in the host country $[9,18,19,20]$. When the motivation is access to natural resources or strategic assets firms would prefer M\&A ODI [21, 22]. This leads to our third hypothesis.

Hypothesis III: multinationals seeking cost savings will prefer Greenfield ODI; those seeking access to natural resources will prefer $M \& A O D I$.

We test these three hypotheses with respect to the ODI mode choices of Chinese multinationals.

\section{Data Illustration}

We combined two datasets to conduct our empirical analysis. 
The first dataset is the China Global Investment Tracker dataset (CGIT), published by the American Enterprise Institute and the Heritage Foundation. The CGIT database contains approximately 2200 large ODI transactions (at least 0.1. billion USD) across diverse industries from 2005 to 2016. It covers almost all large scale ODI transactions by Chinese firms with a total value amounting to roughly 1.5 trillion USD. The dataset includes information on the value, ownership ratio, parent investor, origin country, host country, industry sector and ODI mode choice for transactions.

The second dataset is the Doing Business dataset published by World Bank, from which we extract eight items for 190 economies from 2005 to 2017. These are: starting a business, dealing with construction permits, obtaining electricity, obtaining credit, paying taxes, enforcing contracts, registering property, and trading across borders. The Doing Business dataset provides objective measures of business regulations and their enforcement for 190 economies and for selected cities at the subnational and regional level. The items that we chose provide information on country characteristics that relate to barriers to investment and hence to ODI in a host country.

In order to use the datasets each ODI transaction needs to be matched with the appropriate country characteristic information. In order to do this, we deleted transactions for which there is no corresponding country characteristic information. We also deleted transactions with missing information for any of the following items: host country, ODI mode, value of investment, and industry sector. After data matching and cleaning, we are left with 2,208 usable observations.

Figures 3 and 4 show the number of transactions and the values invested by sector, respectively. From Figure 3, we can see that the three most attractive sectors for investment by Chinese firms are energy, transport and real estate. This is very similar to the ordering from the perspective of total investment value in Figure 4, although metals rank higher than real estate on the basis of value.

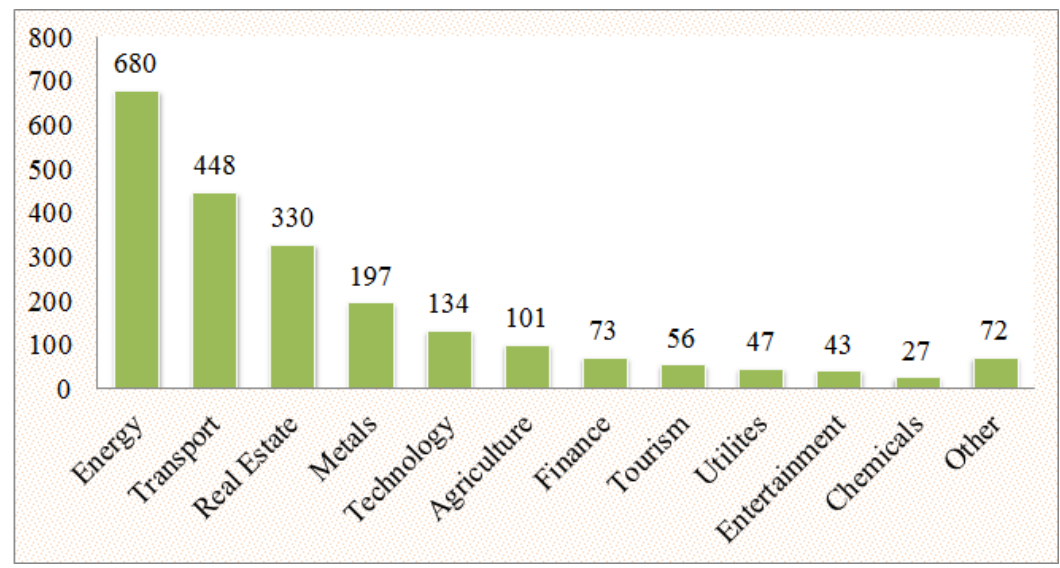

Data Source: China Global Investment Tracker dataset

Figure 3. Transactions Amount in Diverse Industry Sector, 2005 - 2016.

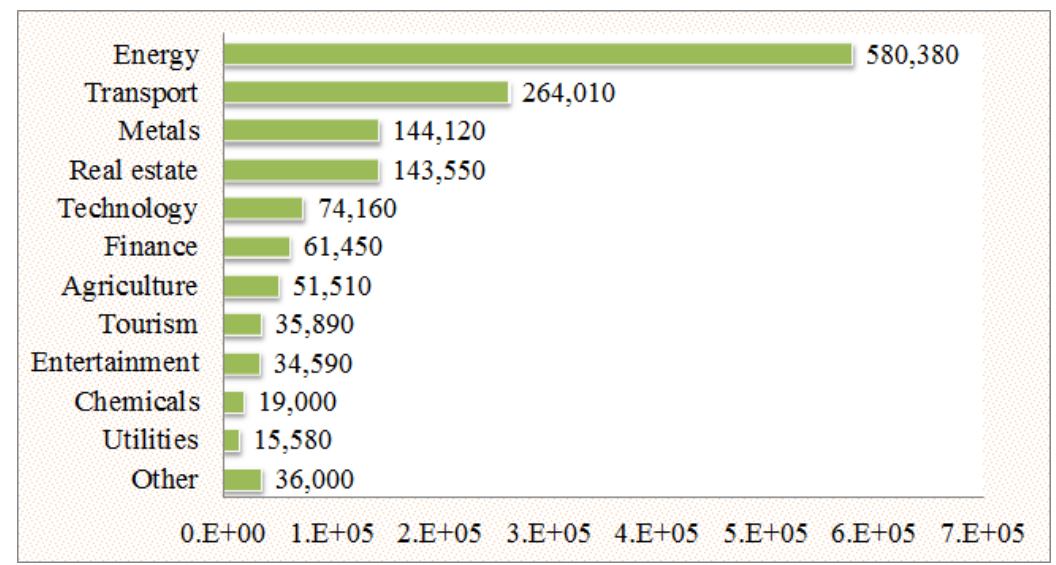

Data Source: China Global Investment Tracker dataset

Figure 4. Value Invested by Industry Sectors (Million USD) 2005 - 2016.

Figures 5 and 6 show the number of transactions by region and their value, respectively. From Figure 5, we can see that the three most attractive regions for Chinese firms in terms of the number of transactions are Sub-Saharan Africa, East Asia and West Asia. From Figure 6, we can see that the three regions that received the most investment in terms of value were Sub-Saharan Africa, Europe and West Asia. 


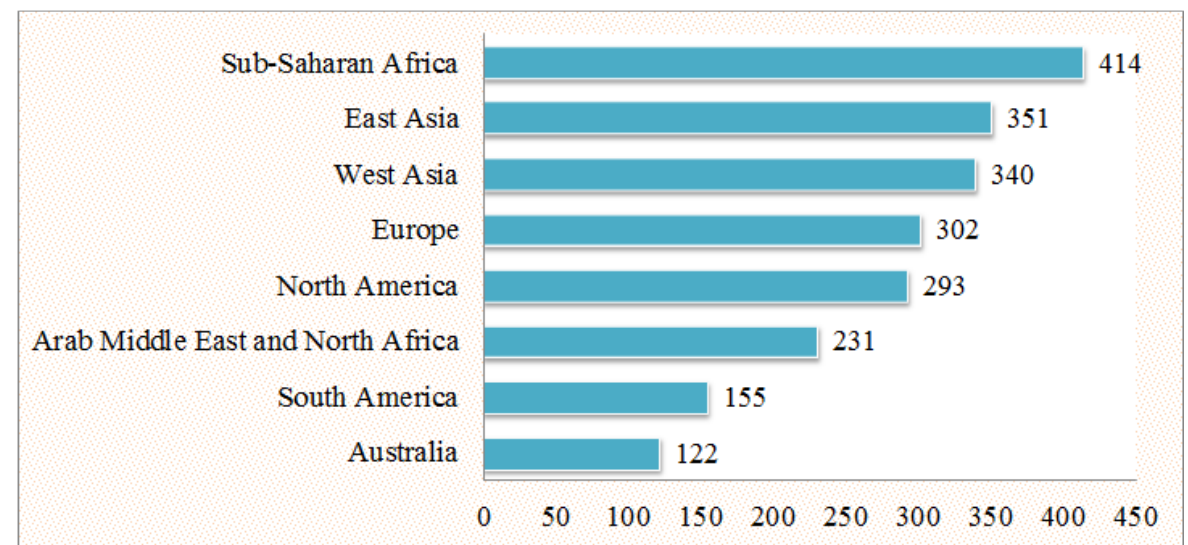

Data Source: China Global Investment Tracker dataset

Figure 5. Number of Transactions by Region 2005 - 2016.

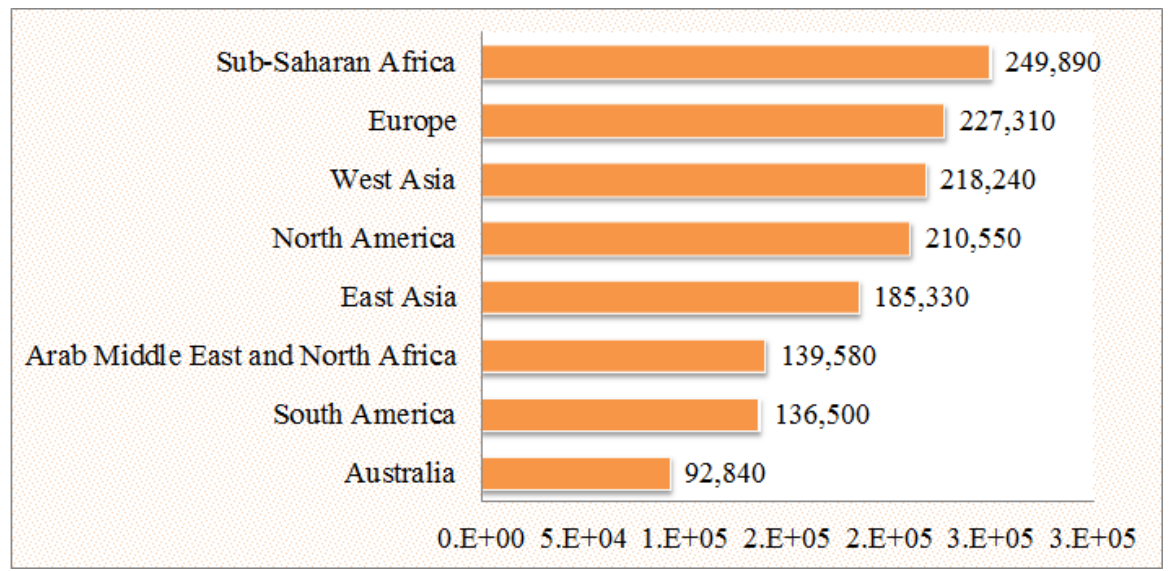

Data Source: China Global Investment Tracker dataset

Figure 6. Value Invested by Region (Million USD) 2005 - 2016.

Figure 7 shows that there are 1,436 Greenfield transactions and 772 M\&A transactions, i.e., $65 \%$ of the transactions are Greenfield. Figure 8 shows that from the perspective of transaction value, $60 \%$ of the investments were Greenfield.

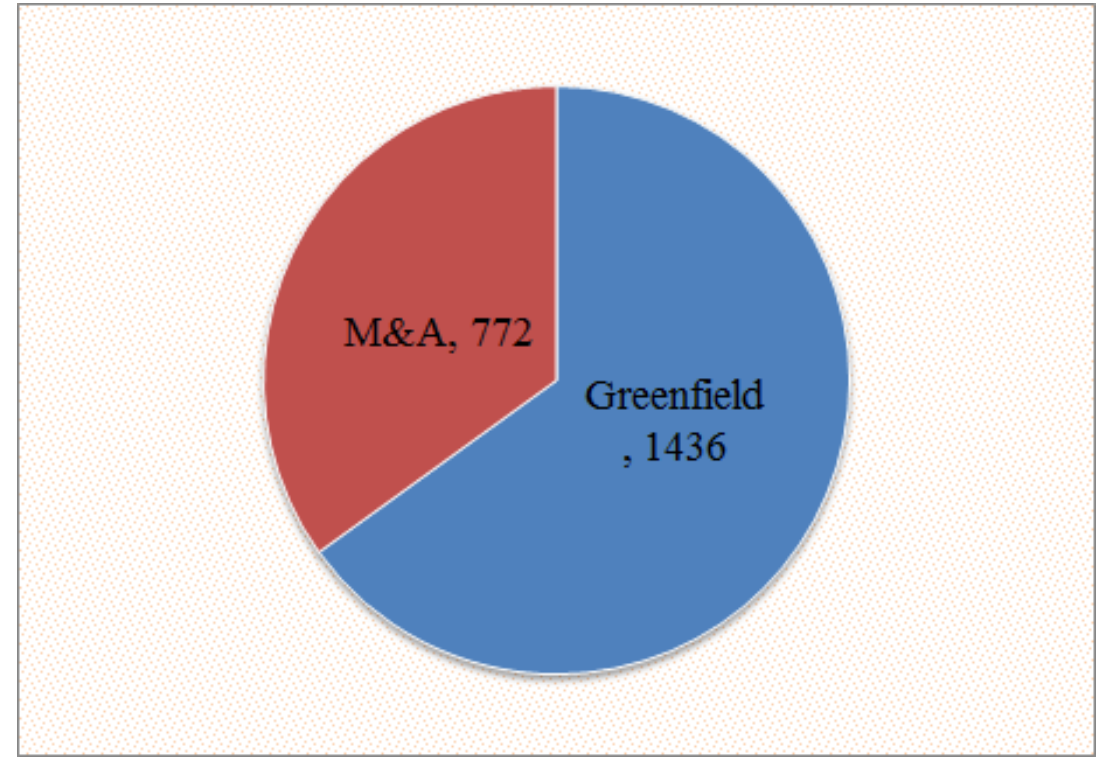

Data Source: China Global Investment Tracker dataset

Figure 7. ODI Mode by Number of Transactions 2005- 2016. 


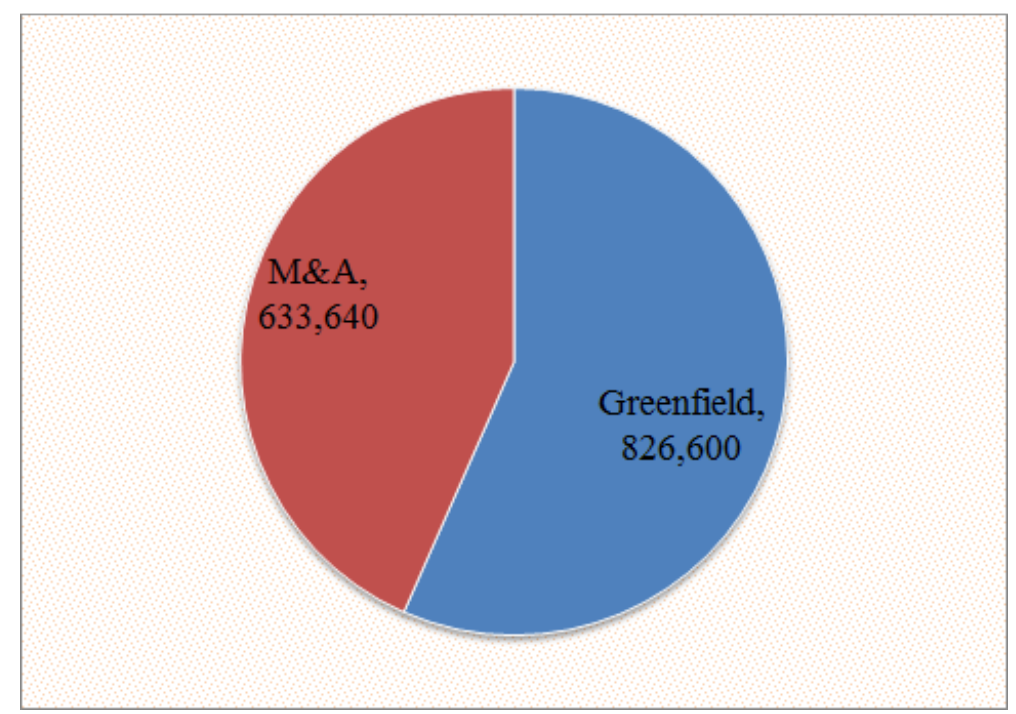

Data Source: China Global Investment Tracker dataset

Figure 8. ODI Mode by Value of Transactions 2005 - 2016.

\section{Empirical Methods}

We use a LOGIT model to test the three hypothesizes. The estimating equation is:

$$
\begin{aligned}
\operatorname{Pr}\left(\text { ODIMode }_{i}=\right. & \left.1 \mid X_{i}\right)=\beta_{0}+\beta_{1} \text { Year }_{i}+\beta_{2} \text { Quantity }_{i}+\beta_{3} \text { SectorMobility }_{i}+\beta_{4} \text { SBDTF }_{i}+\beta_{5} \text { DCPDTF }_{i}+\beta_{6} \text { GEDTF }_{i}+ \\
& \beta_{7} \text { RPDTF }_{i}+\beta_{8} \text { GCDTF }_{i}+\beta_{9} \text { PTDTF }_{i}+\beta_{10} \text { TABDTF }_{i}+\beta_{11} \text { ECDTF }_{i}+\beta_{12} N R_{i}+\beta_{13} L C_{i}+\varepsilon_{i}
\end{aligned}
$$

\section{(i represents the index of every transaction)}

The variables are defined in Table 1.

\begin{tabular}{|c|c|c|c|}
\hline Variables & Definition & Value & Description of Value \\
\hline ODI Mode & ODI Mode Choice & 0 -1 Dummy & $\begin{array}{l}1 \text { if the transaction was Greenfield, and } 0 \text { if the transaction } \\
\text { was M\&A }\end{array}$ \\
\hline Year & Year & Year & In which year the transaction was conducted \\
\hline Quantity & Quantity of Investment & Millions USD & The value of the transaction \\
\hline $\begin{array}{l}\text { Sector } \\
\text { Mobility }\end{array}$ & $\begin{array}{l}\text { Mobility of Capability Requirement for the } \\
\text { Industry }\end{array}$ & 0 - 1 Dummy & $\begin{array}{l}1 \text { denotes that the industry requires mobile capability for } \\
\text { competitiveness, and } 0 \text { means that is requires immobile } \\
\text { capability }\end{array}$ \\
\hline SBDTF & Starting a Business - Distance to Frontier & a scale from 0 to 100 & DTF index of starting a business \\
\hline DCPDTF & $\begin{array}{l}\text { Dealing with Construction Permits - Distance to } \\
\text { Frontier }\end{array}$ & a scale from 0 to 100 & DTF index of dealing with construction permits \\
\hline GEDTF & Getting Electricity - Distance to Frontier & a scale from 0 to 100 & DTF index of getting electricity \\
\hline RPDTF & Registering Property - Distance to Frontier & a scale from 0 to 100 & DTF index of registering property \\
\hline GCDTF & Getting Credit - Distance to Frontier & a scale from 0 to 100 & DTF index of getting credit \\
\hline PTDTF & Paying Tax - Distance to Frontier & a scale from 0 to 100 & DTF index of paying tax \\
\hline TABDTF & Trading Across Borders - Distance to Frontier & a scale from 0 to 100 & DTF index of trading across borders \\
\hline ECDTF & Enforcing Contracts - Distance to Frontier & a scale from 0 to 100 & DTF index of enforcing contracts \\
\hline NR & Rely on Natural Resource or not & 0 - 1 Dummy & $\begin{array}{l}1 \text { means that the industry requires substantial natural } \\
\text { resources, and } 0 \text { means that this does not apply }\end{array}$ \\
\hline LC & Labor Cost & GNI per capita, USD & Used to reflect the level of labor cost in the host economy \\
\hline
\end{tabular}

Table 1. Descriptions of Variables.

The dummy variable for sector mobility indicates whether an industry primarily requires mobile capabilities for competitiveness or whether it requires immobile capabilities. We define this variable for every transaction sample as a reflection of the factor-intensity of the industry which sample belonged to. For example, if the industries rely on non-physical capital intensity, such as technology-intensive and knowledge-intensive, they are identified as mobile sectors, which would include energy, metals, technology, agriculture, chemicals, utilities, transport, and real estate. If the industries rely on physical capital intensity, such as labor-intensive, marketing-intensive and capital-intensive, they are classified as immobile sectors which would include finance, tourism, and entertainment. We directly use the calculation results of Chinese industrial factor-intensity in the past literature to conduct the assignments[23, 24, 25, 26, 27]. 
The distance to frontier (DTF) variables measure the absolute level of regulatory performance as estimated by the World Bank. They show the distance of each economy to the "frontier," which represents the best performance observed for each of the indicators across all economies in the World Bank's sample. This is expressed on a scale from 0 to 100 , where 0 represents the lowest performance and a score of 100 represents the highest level of performance. Thus, for example SBDTF is the index relating to the ease of starting a business in an economy. It is constructed on the basis of the paid-in minimum capital requirement, number of procedures, time and cost for a small- to medium-sized limited liability company to start up and formally operate in economy's largest business city. Details on the construction of the other indices are given in the World Bank's documentation for the database.

The dummy variable NR is to define whether the industry was a nature-resource intensive industry, and we directly use the standard in the well-used past literature. The variable LC is to define the GNI per capita of the host country, and the observations are directly matched from the dataset from World bank Database. We should note that though the transactions' data are treated as cross-section data, all of the variables for country characteristics are treated as panel data, which means that two transactions conducted in the same country in different years would have different values for country characteristic variables.

\section{Results and Implications}

All the DTF variables are designed to capture different aspects of country characteristics, which mean from there should be no multicollinearity. However, for robustness purposes we gradually introduce the variables into the estimation. We take three steps to conduct the test process. In the first step we only include Year, Quantity and SectorMobility in the estimation to test hypothesis I; in the second step we add all the DTF variables, representing the diverse country characteristics, to test hypothesis I and II; in the third step we add $N R$ and $L C$ to test hypothesis I, II and III. The estimation results are shown in Table 2.

Table 2. Estimation Results.

\begin{tabular}{llll}
\hline & (Step 1) & (Step 2) & (Step 3) \\
\cline { 2 - 4 } & ODIMode & ODIMode & ODIMode \\
\hline Year & $-0.0694^{* * *}$ & -0.000544 & -0.00795 \\
& $(-3.63)$ & $(-0.03)$ & $(-0.36)$ \\
Quantity & $-0.000303^{* * *}$ & $-0.000355^{* * *}$ & $-0.000267^{* * *}$ \\
& $(-4.65)$ & $(-5.59)$ & $(-4.14)$ \\
SectorMobility & $1.906^{* * *}$ & $1.364^{* * *}$ & $1.634^{* * *}$ \\
& $(6.91)$ & $(7.74)$ & $(8.30)$ \\
SBDTF & & $-0.0146^{*}$ & -0.0119 \\
& & $(-2.46)$ & $(-1.94)$ \\
DCPDTF & & -0.000149 & $0.0114^{*}$ \\
& & $(-0.03)$ & $(2.39)$ \\
GEDTF & & -0.00434 & -0.00433 \\
& & $(-1.16)$ & $(-1.12)$ \\
RPDTF & $0.0108^{*}$ & $0.0140^{* *}$ \\
& & $(2.18)$ & $(2.68)$ \\
GCDTF & $-0.0162^{* * *}$ & $-0.0124^{* * *}$ \\
& & $(-4.93)$ & $(-3.53)$ \\
\hline
\end{tabular}

\begin{tabular}{llll}
\hline & (Step 1) & (Step 2) & (Step 3) \\
\cline { 2 - 4 } & ODIMode & ODIMode & ODIMode \\
\hline PTDTF & & -0.0000690 & $0.0151^{* * *}$ \\
& & $(-0.02)$ & $(3.57)$ \\
TABDTF & & $-0.0179^{* * *}$ & $-0.00915^{*}$ \\
& & $(-4.65)$ & $(-2.19)$ \\
ECDTF & & $-0.0348^{* * *}$ & $-0.0196^{* * *}$ \\
& & $(-6.23)$ & $(-3.35)$ \\
NR & & & $-0.802^{* * *}$ \\
& & & $(-6.05)$ \\
LC & & & $-0.0000509^{* * *}$ \\
& & & $(-11.91)$ \\
Constant & $138.8^{* * *}$ & 5.873 & 17.99 \\
& $(3.61)$ & $(0.14)$ & $(0.40)$ \\
Insig2u & & & \\
cons & -1.517 & -10.79 & -8.733 \\
& $(-0.58)$ & $(-0.61)$ & $(-0.43)$ \\
Samples Amount & 2208 & 2208 & 2184 \\
\hline
\end{tabular}

$t$ statistics in parentheses, ${ }^{*} p<0.05,{ }^{* *} p<0.01,{ }^{* * *} p<0.001$

On the basis of Table 2, we can make the following observations.

The coefficient on SectorMobility is significantly positive in all three estimation steps, which provides strong support for hypothesis I. In industry sectors that require more mobile capabilities, such as technology and knowledge, we observe more Greenfield ODI behavior. This result supports the argument made by Nocke and Yeaple[1]. Cross-border factor mobility plays an important role in Chinese multinationals' ODI mode choice and the international organization of production varies across industries.

The coefficient on RPDTF (registering property) in the second and third steps is significantly positive, while the coefficients on GCDTF (ease of obtaining credit) and ECDTF (enforcing contracts) are significantly negative. This means that in a host country where it is easier to register permits, Chinese multinationals prefer Greenfield investment. In an environment which is conducive to obtaining credit and enforcing contracts, Chinese multinationals prefer M\&A. The results also show that a higher TABDTF (ease of trading across borders) decreases the probability of choosing Greenfield1, which is consistent with what has been observed in ODI between the USA and Europe[1]. Generally speaking, the international organization of production varies across countries, which means that hypothesis II is supported by the data.

The coefficients on NR (natural resources) and LC (labor costs) are both significantly negative in step 3, which supports hypothesis III. For industries that rely on natural resources or in host economies with higher labor costs, Chinese multinationals prefer M\&A ODI. Considering that many economies have restrictions on Greenfield FDI in natural resource fields, the only option for a foreign firm may be through merger with a local company. With regards to labor cost, the estimation result shows that high labor costs in a host

1 Note that TABDTF is the distance to frontier index of trading across borders. A higher score of this variable means it is closer to frontier, which equals to fewer trading obstacles rather than more. This is the reason why a negative coefficient demonstrated $T A B D T F$ is positive for Greenfield but negative for M\&A. 
country will decrease the probability that Chinese multinationals will choose Greenfield. Higher labor costs have a negative influence on the ODI motivation for cost saving or efficiency promotion.

Comparing the estimates from step 3 to those from step 1, we note that after including the $N R$ and $L C$ variables, the coefficient on SectorMobility decrease a little. The reason for this is that there are some industry sectors which are both immobile and natural resource based, such as energy, mining, agriculture and metals. The multinational firms in these industries both prefer Greenfield due to the requirement for mobility of capabilities but also prefer M\&A due to the requirement to obtain access to natural resources. Therefore, introducing NR decreases the correlation between the probability of choosing Greenfield ODI mode and Sectormobility.

Finally, the Quantity variable has a robust significant negative coefficient. It is intuitive that most M\&A would need more capital than Greenfield due to the need to pay acquisition premiums for established firms.

In general, all three hypothesizes are supported with respect the ODI behavior of Chinese multinationals, which means that cross-border factor mobility plays an important role in their ODI mode choice decisions.

\section{Conclusions and Prospects}

Recent theoretical progress in the field of foreign direct investment and the international organization of production, which seeks to explain the international organization of production through firm heterogeneity, can provide understanding at the micro-level on the internationalization behavior of multinationals. Our work contributes to empirical evidence in this field.

Based on 2,208 Chinese multinationals' large scale ODI transactions, we examine the relationship between cross-border factor mobility and ODI mode choices. Our results support the view that cross-border factor mobility plays an important role in decision process for ODI mode choice by Chinese multinationals, and that the choice varies across industries. This provides evidence to support the recent theoretical progress in the field by Nocke and Yeaple[1].

Our results also show that ODI mode choice by Chinese multinationals varies across countries, which implies that the cross-border factor mobility of capabilities is influenced by the characteristics of host economies. Specifically, ease of registering property in a host economy leads to a higher probability that Chinese multinationals will choose Greenfield, while ease of obtaining credit, enforcing contracts and trading across borders leads to a higher probability of choosing M\&A. Our results also show that the probability of choosing M\&A increases when an industry relies on obtaining access to natural resources or ODI is being undertaken in a host economy with high labor costs.

However, in our empirical process, there were still two short boards should be improved but could not be done due to the shortage of dataset. Firstly, There might be kind of omitted variable problem as a result of that only 8 country-level variables related to the business environment and three industry-level variables were well-controlled in the estimation. Due to the shortage of firm-level data, we can only have the financial information of the listing firms, so if we link the transaction data with the firm data, there would be a huge loss of ODI information and even the estimation could not be done. Furthermore, Chinese multinationals have invested in lots of developing countries especially neighbors and China has a long border, there were no enough information to control the exact gravity variables such as physical distance and cultural distance. Secondly, there might be a sampling problem as a result of that only large transactions over 0.1 billion USD are analyzed in our estimation, it is not the whole sample of Chinese multinationals ODI, which would decrease the meaning of estimation results. We could not track every transaction within diverse amount levels, and usually rather than one small-scale transaction, one transaction with a relative huge amount has a bigger probability to be reported by the initial company or noticed by the news press, which lead to the shortage of available data and this dose be a tough problem in the future research. Even though, our research has used the best matched dataset so far to reflect the endogenous motivation of Chinese multinationals' ODI behaviors, which has significant implications to the following work especially to pursue the micro-level understanding of Chinese multinationals' international production of organization, and the two short boards will be well-alleviated by the data accumulation in the future.

\section{References}

[1] Nocke V., Yeaple S. Cross-border mergers and acquisitions vs. greenfield foreign direct investment: The role of firm heterogeneity [J]. Journal of International Economics, 2007, 72 (2), 336-365.

[2] Ivashina V., Scharfstein D. Bank lending during the financial crisis of 2008 [J]. Journal of Financial economics, 2010, 97 (3), 319-338.

[3] Beltratti A, Paladino G. Is M\&A different during a crisis? Evidence from the European banking sector [J]. Journal of Banking \& Finance, 2013, 37 (12), 5394-5405.

[4] Melitz M. J. The impact of trade on intra - industry reallocations and aggregate industry productivity [J]. Econometrica, 2003, 71 (6), 1695-1725.

[5] Helpman E, Melitz M. J., Yeaple S. R. Export Versus FDI with Heterogeneous Firms [J]. American Economic Review, 2004, 94 (1), 300-316.

[6] Castellani, D., A. Zanfei. Internationalization, Innovation and Productivity: How Do Firms Differ in Italy [J]. World Economy, 2004, 30 (1), 156-176.

[7] Arnold, J. M., K. Hussinger. Exports versus FDI in German Manufacturing: Firm Performance and Participation in International Markets [J]. Review of International Economics, 2010, 18 (4), 595-606. 
[8] Engel, D., V. Procher. Export, FDI and Firm Productivity [J]. Applied Economics, 2012, 44 (15), 1931-1940.

[9] Nocke V., Yeaple S. An assignment theory of foreign direct investment [J]. The Review of Economic Studies, 2008, 75 (2), 529-557.

[10] Wang A. The choice of market entry mode: cross-border M\&A or Greenfield investment [J]. International Journal of business and management, 2009, 4 (5), 239-245.

[11] Schiffbauer M., Siedschlag I., Ruane F. Do foreign mergers and acquisitions boost firm productivity? [R]. ESRI working paper, No. 305.2017.

[12] Stiebale J., Trax M. The effects of cross - border M\&As on the acquirers' domestic performance: firm - level evidence [J]. Canadian Journal of Economics, 2011, 44 (3), 957-990.

[13] Kalkbrenner E. Acquired versus Non-Acquired Subsidiaries-Which Entry Mode do Parent Firms Prefer [R]. NRN Working Paper, NRN: The Austrian Center for Labor Economics and the Analysis of the Welfare State. 2010.

[14] Byun Hyung-suk, Lee Hyun-Hoon, Park Cyn-Young. Assessing Factors Affecting M\&As Versus Greenfield FDI in Emerging Countries [R]. Asian Development Bank Economics Working Paper Series No. 293. 2012.

[15] Ayca, T. K. Cross-Border M\&A vs. Greenfield Investments: Does Corruption Make A Difference? [R]. MPRA Working Paper, No. 42857. 2012.

[16] Dunning J. H. International Production and the Multinational Enterprise (RLE International Business) [M]. Routledge. 2012.

[17] Buckley P. J, Clegg L. J., Cross A. R., et al. The determinants of Chinese outward foreign direct investment $[\mathrm{J}]$. Journal of international business studies, 2007, 38 (4), 499-518.

[18] Hijzen A., Grag H., Manchin M. Cross-border mergers and acquisitions and the role of trade costs $[\mathrm{J}]$. European Economic Review, 2008, 52 (5), 849-866.

[19] Chen M. X, Moore M O. Location decision of heterogeneous multinational firms [J]. Journal of International Economics, 2010, 80 (2), 188-199.

[20] Chen M. X. Interdependence in multinational production networks [J]. Canadian Journal of Economics, 2011, 44 (3), 930-956.

[21] Huang Y., Wang B J. Chinese outward direct investment: Is there a China model? [J]. China \& World Economy, 2011, 19 (4), 1-21.

[22] Huang Y., Wang B J. Investing overseas without moving factories abroad: The case of Chinese outward direct investment [J]. Asian Development Review, 2013, 1, 85-107.

[23] Ma Y, Tang H, Zhang Y. Factor intensity, product switching, and productivity: Evidence from Chinese exporters [J]. Journal of International Economics, 2014, 92 (2): 349-362.

[24] Yan Lili, Wu Lixue. Input output structure, industry heterogeneity and China's economic fluctuation [J]. World economy (in Chinese), 2017, 40 (08): 3-28.

[25] Zhang Wanli, Wei Wei. Factor density, industrial agglomeration and productivity improvement: empirical research from micro data of Chinese enterprises [J]. Finance and trade research (in Chinese), 2018, 29 (07): 28-41.

[26] Zhang Bochao, Jin laiqun, MI Yanxia. Resource mismatch and industrial structure upgrading among manufacturing elements with heterogeneity in China [J]. Contemporary economic management (in Chinese), 2019, 41 (02): 60-67.

[27] He Binfeng, Fang Sheng, Feng Jin. An Empirical Study on energy conservation, emission reduction and stable growth based on the concentration of industrial factors [J]. Industrial technology and economy (in Chinese), 2017, 36 (01): 10-14. 